\title{
FORMAÇÃO INICIAL EM EDUCAÇÃO FÍSICA E AS REPERCUSSÕES DA PROPOSIÇÃO DE LICENCIATURA AMPLIADA NO CEDF/UEPA ${ }^{21}$
}

\author{
Giselle dos Santos Ribeiro \\ Universidade do Estado do Pará, Belem, Pará, Brasil. \\ Jessica Regina Sales Lima \\ Universidade do Estado do Pará, Belem, Pará, Brasil. \\ Anibal Correia Brito Neto \\ Universidade do Estado do Pará, Belem, Pará, Brasil. \\ Marta Genú Soares \\ Universidade do Estado do Pará, Belem, Pará, Brasil.
}

\begin{abstract}
Resumo: Discute os limites e possibilidades da implementação da proposta de licenciatura ampliada assumida pelo CEDF/UEPA. Por meio de fontes bibliográficas, documentais e orais revela o processo de judicialização dos impasses na Formação em Educação Física, as contradições na implementação da proposta formativa devido à falta de consenso sobre os projetos em disputa e a adoção acrítica, por parte de professores universitários, de discursos que não apreendem a totalidade da matéria referente a legislação educacional brasileira. Conclui sobre a inviabilidade de desfechos consensuais, o que demanda aos defensores da proposta de formação ampliada a desnaturalização das interpretações jurídico-educacionais em favor de um viés político.
\end{abstract}

Palavras-Chave: Educação Física. Formação de Recursos Humanos. Política de Educação Superior. Currículo.

\section{Introdução}

Há uma década da instituição de Diretrizes Curriculares Nacionais (DCN) para os Cursos de Graduação em Educação Física (BRASIL, 2004), ao invés do esclarecimento da comunidade acadêmico-científica e do entorno social, persiste a imprecisão, disputa, cooptação e coerção sobre os limites e possibilidades ensejados por estas orientações curriculares e pelo conjunto do ordenamento legal brasileiro.

Tal constatação pode ser confirmada em uma breve consulta aos atos normativos do Conselho Nacional de Educação (CNE) (BRASIL, 2005a; 2011a; 2012a), ou ao vasto processo de judicialização da relação entre formação e exercício profissional em Educação 
Física que tem exigido atuação permanente do Ministério Público Federal (MPF) e dos Tribunais Regionais Federais (TRF) em diversos Estados brasileiros ${ }^{22}$.

Da análise deste vasto material jurídico é possível identificar uma permanente ingerência do Conselho Federal de Educação Física (CONFEF) e dos respectivos Conselhos Regionais de Educação Física (CREF), os quais tem extrapolado indevidamente as competências relacionados a fiscalização do exercício profissional, mesmo com a recorrente advertência do CNE acerca da inconveniência e ilegalidade desta interferência nas atividades escolares e acadêmicas que são reguladas pelo sistema de ensino (BRASIL, 2002; 2005a; 2005b; 2006; 2011a; 2011b; 2012a).

Atentos a este movimento mais geral que tem determinado a disputa no campo da formação em Educação Física e mobilizados pelas implicações da regulamentação da profissão em diversas dimensões desta prática social, a qual segundo Almeida, Montagner e Gutierrez (2009) exige a ampliação do debate e atração de novos participantes para este campo de discussão e reflexão, abordaremos a repercussão das DCN no âmbito dialético da produção/reprodução de propostas para a formação em Educação Física.

A relevância do estudo está compreendida na tese defendida por Taffarel (1997) e Taffarel e Santos Júnior (2010), de que o embate travado no campo da formação de professores pode estabelecer novas referências para o processo de manutenção ou ruptura com a forma de organizar a vida em sociedade e, ainda, na insuficiência de produção sistematizada que ratifique ou derroque a suspeita de Lemos et al. (2012, p. 44), de que as mudanças trazidas pelas reformas curriculares se materializaram através de "uma aceitação acrítica do que está posto, com poucos elementos de ressignificação sobre as normas estabelecidas oficialmente".

O campo empírico de estudo é a proposta formativa implementada pelo Curso de Educação Física da Universidade do Estado do Pará (CEDF/UEPA), por trazer o anúncio de uma perspectiva inovadora para área, uma licenciatura plena em Educação Física, de caráter ampliado (UEPA, 2007). Tal inciativa, conforme tem demonstrado os Fóruns das licenciaturas com formação ampliada em Educação Física ${ }^{23}$, não se configura como hegemônica neste campo, ampliando, assim, a relevância da exposição.

Logo, o objetivo geral do estudo se configurou em discutir os limites, contradições e possibilidades da implementação da licenciatura ampliada proposta pelo CEDF/UEPA. Como objetivos específicos, delineamos: a) sistematizar os parâmetros teóricos e metodológicos da concepção de licenciatura ampliada exposta na literatura especializada e no Projeto Político Pedagógico do CEDF/UEPA; b) identificar o nível de apropriação e a concepção dos docentes do CEDF/UEPA sobre a proposta pedagógica oficial do Curso no que se refere à concepção de licenciatura ampliada e; c) analisar as possíveis implicações das contradições entre o anunciado na proposta oficial e o concebido pelos docentes para a materialização do currículo do CEDF/UEPA.

Tivemos acesso a um significativo número de ajuizamento de Ações Civis Públicas com este fim no sítio dos Tribunais Regionais Federais de diversos Estados, entre os quais: Bahia; Ceará, Distrito Federal, Goiás, Pará, Paraíba, Paraná, Rondônia, Roraima, Santa Catarina e Tocantins.

23 A primeira edição do Fórum foi realizada na Escola Superior de Educação Física e Fisioterapia do Estado de Goiás da Universidade do Estado de Goiás (ESEFFEGO/UEG), no período de 30 de novembro a 01 de dezembro de 2012 e a segunda edição na Faculdade de Educação da Universidade Federal da Bahia (FACED/UFBA) no período de 31 de outubro de 2013 a 01 de novembro de 2013. 


\section{Decisões metodológicas}

A metodologia desta investigação pautou-se nos fundamentos do materialismo histórico dialético, entendido na acepção de Frigotto (2006), como uma tríade entre concepção de mundo, método de investigação e práxis de intervenção na realidade.

Configurou-se como uma pesquisa de campo, na modalidade estudo de caso. As técnicas utilizadas foram: análise bibliográfica da literatura especializada sobre a concepção de formação ampliada em Educação Física, análise documental da proposta oficial do CEDF/UEPA e entrevista semiestruturada realizada com 16 (dezesseis) docentes do CEDF/UEPA sobre os limites e possibilidades da implementação da concepção de formação ampliada.

A amostra de sujeitos selecionados teve caráter intencional, apresentando como critério de inclusão: a) serem efetivos da carreira do magistério superior da UEPA; b) terem formação inicial em cursos superiores de Educação Física; c) estarem lotados no Campus de Belém-Pará; d) estarem no efetivo exercício da sua função docente no momento da pesquisa; e) concordarem com a participação na pesquisa através da assinatura do Termo de Consentimento Livre e Esclarecido (TCLE).

Por se tratar de uma pesquisa que envolveu seres humanos, assumimos ao longo da investigação a responsabilidade ética com todas as diretrizes e normas regulamentadoras contidas na Resolução do Conselho Nacional de Saúde n. 466/12 (BRASIL, 2012b). O parecer de aprovação da pesquisa foi emitido pelo Comitê de Ética em Pesquisa CCBS/UEPA - Curso de Educação Física - Campus III, sob o número 265.043.

\section{A concepção de licenciatura ampliada em Educação Física}

$\mathrm{Na}$ atualidade, a defesa por uma formação ampliada é formulada de modo mais consistente a partir do entendimento de que em qualquer campo de atuação, a ação pedagógica é a base da formação acadêmica e do trabalho. Portanto, a docência, entendida como trabalho pedagógico é a identidade epistêmica, e isso pode ser verificada pelos fatos quando nos reportamos à ação profissional e identificamos os sentidos, significados, finalidades, meios e métodos ao longo da história (TAFFAREL; SANTOS JÚNIOR, 2005, p. 127).

$\mathrm{Na}$ perspectiva de garantir às gerações futuras a apropriação do saber historicamente construído, precisamos de formas sistematizadas de ensino aprendizagem e, na Educação Física, o trato com o conhecimento da cultura corporal não é diferente, isso, inclusive, simboliza a atuação e função social do professor da área (FALCÃO, 2004; TAFFAREL et al., 2006; CRUZ, 2011; TAFFAREL, 2012).

Porém, esta transmissão do saber pela educação física não pode acontecer sem um engajamento político pedagógico a um dado projeto histórico pois, conforme alerta Taffarel (1998), as situações educacionais constituídas no seio do sistema capitalista servem ao "amoldamento subjetivo" de uma classe sobre a outra, intensificando, assim, a alienação social.

Compreender o trabalho do professor de educação física, pautado no caráter de desconstrução da ideologia dominante, implica pensar o currículo como espaço político, neste sentido, a formação de professores deve ser orientada por um método de apreensão, explicação e transformação da realidade, o materialismo histórico dialético.

Para uma articulação substancial entre propostas educacionais e projetos históricos de longo alcance, a categoria trabalho precisa ser tomada como princípio educativo, já que o 
mesmo é considerado dimensão fundante do ser social, logo, pressuposto essencial para a construção de um novo projeto de formação humana. Entender o trabalho como inerente a vida humana implica discutir como o homem, especialmente por meio do seu corpo, se inseriu na sociedade e no mundo do trabalho, vendendo sua força de trabalho através do capital de maneira a "reproduzir formas específicas para servir às necessidades do sistema" (CRUZ, 2011, p. 32).

Nessa lógica de pensamento, a formação de professores de educação física precisa se vincular a uma perspectiva que conceba o homem como produtor e reprodutor de seus meios de vida e, por conseguinte, das transformações do meio que o cerca, no sentido histórico, cultural, social e material, onde o trabalho se estabelece como mediador da construção cultural de um povo (TAFFAREL et al., 2006).

Taffarel (1998; 2012), Falcão (2004), Taffarel et al, (2006) e Cruz (2011) mobilizados por tal projeto de formação humana resgatam a necessidade da efetivação do conceito marxiano de omnilateralidade, entendido como a possibilidade de desenvolver todas as capacidades e potencialidades humanas, em contraposição à especialização e fragmentação estabelecidas pela lógica do capital. Nesta perspectiva, a fragmentação da formação em educação física, propalada como medida essencial para a qualificação da formação, expressa, no fundo, a negação de conteúdos socialmente relevantes para o fortalecimento da luta de classes na perspectiva dos trabalhadores.

Diante da proposta de formação, ao invés da predominância de um conhecimento fracionado, a cultura corporal é defendida como direito inalienável para uma formação ampliada, expressando as relações corporais constantes entre o homem e a natureza de forma dialética, ambos em processo de construção e transformação, objetivando a superação do processo alienatório.

\section{Limites, contradições e possibilidades da licenciatura ampliada no CEDF/UEPA}

Em 2008, o CEDF/UEPA passou a efetivar uma nova proposta para a formação em Educação Física no Estado do Pará. Pautados nos estudos epistemológicos e curriculares da formação profissional, o Curso fez a opção pela modalidade caracterizada como "Licenciatura Plena em Educação Física" (UEPA, 2007, p. 10), propondo uma concepção

[...] de caráter ampliado em Educação Física com formação generalista, humanista, crítica e reflexiva, pautada em princípios éticos, políticos, pedagógicos e com base no rigor científico, cuja intervenção profissional seja qualificada para o exercício de atividades profissionais [...] com base na atividade docente expressa no trabalho pedagógico em diferentes campos de trabalho, mediado pelo objeto - práticas corporais, esportivas e do lazer (UEPA, 2007, p. 33)

A partir desta referida base epistemológica, a proposta pedagógica indica que a formação em Educação Física deve estabelecer relações capazes de responder aos problemas encontrados tanto na escola, quanto nas academias, nas escolinhas de esportes, nas diversas ações de lazer, enfim, nos distintos ambientes educacionais de intervenção do professor de Educação Física.

Para tanto, realiza um exame crítico dos determinantes que forjaram as "novas ocupações profissionais" da área e se opõe a uma formação que vise apenas fornecer os 
recursos humanos para as "novas tendências" do mercado. Logo, o CEDF/UEPA passa a se posicionar a favor de outra lógica para a formação.

Defendemos a importância do debate sobre o mundo do trabalho, para realizar a discussão sobre a exploração do trabalho humano. De maneira que os graduandos possam obter ferramentas necessárias para a superação da lógica do mercado de trabalho, que avançam para a desumanização do homem, por intermédio de relações de submissão entre trabalhadores e patrões (UEPA, 2007, p. 30)

O documento ainda infere diversas críticas a concepção de Educação Física predominante ao longo da história, visualizada de maneira fragmentada, com enfoque voltado estritamente para a utilidade imediata, a produtividade e o rendimento, e apresenta como perspectiva superadora proposta pautada na acepção da Educação Física como prática social.

Neste sentido, na apropriação do Projeto Político Pedagógico em vigor no CEDF/UEPA, identificamos que a opção pelo caráter ampliado não está assentada em uma lógica positivista de justaposição das partes, muito menos em uma perspectiva formal e simplista de mediação, colaboração e/ou conciliação de projetos históricos antagônicos de sociedade e formação, mas na demarcação clara dos pressupostos filosóficos que devem orientar a formação dos futuros professores de Educação Física da UEPA, para tanto, anuncia uma forma específica de organização curricular, trato com o conhecimento, avaliação e sistematização das aulas, objetivando, assim, uma formação generalista, humanista, crítica e reflexiva.

No entanto, a análise da apropriação destes pressupostos, por parte dos docentes do CEDF/UEPA, demonstrou níveis diferenciados de reconhecimento e assimilação da mesma. Os registros do Quadro 1 apontam que menos da metade dos entrevistados domina satisfatoriamente a proposta em tela, enquanto a maioria entende parcialmente, apresenta incompreensões, ou não consegue versar sobre a mesma.

Quadro 01 - Concepção de licenciatura ampliada dos docentes do CEDF/UEPA

\begin{tabular}{|c|c|}
\hline CATEGORIAS EXPLICATIVAS & $\begin{array}{l}\text { RECORRÊNCI- } \\
\text { AS }\end{array}$ \\
\hline $\begin{array}{l}\text { Domínio significativo da proposta de licenciatura am- } \\
\text { pliada }\end{array}$ & $\begin{array}{l}\text { D2, D4, D8, D9, } \\
\text { D11, D13 e D16 }\end{array}$ \\
\hline Domínio parcial da proposta de licenciatura ampliada & D1 e D15 \\
\hline Incompreensão da proposta de licenciatura ampliada & $\begin{array}{l}\text { D3, D6, D7, D10 e } \\
\text { D12 }\end{array}$ \\
\hline
\end{tabular}

Não conseguiram versar sobre a proposta de licencia- $\quad$ D5 e D14 02

\section{tura ampliada}

Fonte: registro das entrevistas com docentes do CEDF/UEPA

Segundo a categorização adotada, e a classificação em grupos dos dados coletados, os integrantes do primeiro grupo são considerados como num nível satisfatório de compreensão da proposta de licenciatura ampliada, pois conseguem articular os parâmetros orientadores essenciais desta concepção, sem apresentar contradições internas que comprometam a explicação do objeto. O sujeito D16 sintetiza de maneira clara a forma de apreensão deste grupo. 
Trata-se da formação generalista, baseada numa concepção Marxiana de educação e de formação humana omnilateral, não vê a formação apenas numa perspectiva pragmática, de adequação dos profissionais ao mercado de trabalho, mas uma formação mais ampla, que busca inclusive que os alunos, os egressos do curso, atuem de forma a construir o processo de superação da sociedade vigente, que é a sociedade capitalista (SUJEITO D16).

O segundo grupo apresentou domínio considerado parcial, pois em seus argumentos deixam transparecer que reconhecem isoladamente alguns parâmetros da licenciatura ampliada, mas na essência, demonstram contradições que inviabilizam a compreensão da totalidade. Entre os integrantes deste grupo, o sujeito D15 ao mesmo tempo que reconhece o enfoque materialista histórico, a cultura corporal e a relação entre pressupostos axiológicos e intervenção docente, reduz a intervenção desta proposta ao espaço escolar, contradizendo os fundamentos da licenciatura ampliada, que segundo Taffarel e Santos Júnior (2010, p. 38)

[...] não é preparar o futuro professor para adaptar-se ao local onde vai atuar. Ao contrário, queremos que ele seja formado sob uma base sólida o bastante que o permita contextualizar sua intervenção e a partir daí que seja capaz de dosar, garantir uma sequência lógica e sistematizar o conhecimento que será tratado.

Já no terceiro grupo de professores, foram classificados como possuidores de uma incompreensão da proposta, pois reduzem o significado da formação ampliada a necessidade de garantir um máximo de habilidades profissionais para atendimento do mercado de trabalho em expansão, como bem expressa o sujeito D10, que ao explicar como implementa sua intervenção, informa: "[...] eu procuro ministrar a minha disciplina observando a necessidade que nós conhecemos aí nas escolas, nos clubes, nas academias, nos condomínios, preparando nossos alunos pra enfrentar esse mercado de trabalho".

Nozaki (2004) esclarece que formar para o mercado de trabalho significa voltar as intenções pedagógicas prioritariamente para a instrumentalização das competências exigidas pelos postos de trabalho com maior absorção dos trabalhadores, ou seja, de onde é mais fácil a venda da "mercadoria" força de trabalho, apenas subordinando-se as relações capitalistas, sem ao menos examinar suas contradições, no que tange à exploração do trabalho humano.

No último grupo, 02 (dois) professores não conseguiram versar sobre a concepção de licenciatura ampliada, ora afirmando que não conhecem tal proposta outrora tergiversando para argumentos do tipo "alguns professores falam que não existe mais esse termo licenciatura ampliada legalmente" (SUJEITO D14).

Quanto aos limites e avanços expressos na implementação da licenciatura ampliada no CEDF/UEPA, o embate entre uma formação para o atendimento das demandas do capital ou para a superação das contradições do mundo do trabalho retorna como pauta central. O quadro 2 demonstra os principais avanços segundo os docentes do CEDF/UEPA. 
Quadro 2 - Avanços da licenciatura ampliada segundo docentes do CEDF/UEPA

\section{CATEGORIAS EXPLICATIVAS RECORRÊNCI-}

AS

Visão de formação que supera a lógica de adequação ao mercado de trabalho

D2，D4，D8，D9， 06

D13, D16

Trouxe a perspectiva da contínua interação entre teo- D1, D3, D11 e D15 04

ria e prática

Qualificação da intervenção do futuro professor no es- D10 $\quad 01$

paço escolar

$\begin{array}{lll}\text { Mobilização da comunidade acadêmica para o estudo } & \text { D8 } & 01\end{array}$

das diferentes posições sobre a formação

Reconhecimento dos diferentes campos de intervenção $\quad$ D16 01

da Educação Física

Não mencionaram avanços na proposta

D5, D6，D7，D12， 05

D14

Fonte: tabulação das entrevistas com docentes do CEDF/UEPA

Além da menção a aspectos fundamentais, tais como a relação teoria e prática, a mobilização e qualificação da intervenção na escola e em outros campos de intervenção, localizamos como ação mais expressiva da concepção de licenciatura ampliada, a discussão da necessidade de superação da lógica de uma formação voltada exclusivamente às demandas do mercado de trabalho, levantada por 06 (seis) docentes, como demonstra o sujeito D2:

[...] esse projeto, ele veio com essa intenção de uma formação inicial, que fosse para vários espaços educacionais e que não fosse só para o mercado de trabalho e sim pro mundo do trabalho, que não fosse aquilo assim: "eu sou empregado e é isso que eu tenho que obedecer", faz parte mesmo de todo esse processo de construção humana, construção da sua vida, de uma pessoa crítica.

Taffarel e Santos Júnior advertem que a luta de classes está presente na disputa de projetos para a formação de professores, logo, os envolvidos neste processo tendem a as sumir posições necessárias aos interesses de uma classe social, em que "de um lado o projeto de formação adequado ou subsumido a manutenção da escola capitalista com sua perspectiva alienadora. De outro o projeto de formação crítico-superador que visa uma contra internalização, que busca uma formação para além do capital” (2010, p. 14-15).

Tal disputa fica explícita, principalmente quando confrontamos os avanços apontados anteriormente com os limites indicados no quadro 3, com destaque para a indicação de quatro docentes quando se referem que a proposta não atende as demandas do mercado de trabalho. 
Quadro 3 - Limites da Licenciatura ampliada segundo docentes do CEDF/UEPA CATEGORIAS EXPLICATIVAS RECORRÊNCIAS

Ausência e/ou incipiência de conhecimentos ou componentes curriculares na proposta pedagógica

D3，D5，D6，D7， 10

D8, D9, D10, D12,

D14 e D16

Limitada apropriação teórica da proposta pedagógica por parte da comunidade acadêmica

D1，D2，D3，D4， 06

Carência de momentos formativos do corpo docente

D8 e D11

D4, D8, D11, D13 05

e D15

Falta de diálogo e trabalho coletivo entre o corpo docente

D2, D4, D8, D13 e 05

Disputas políticas entre o corpo docente

D15

Falta de compromisso de integrantes do corpo docente D1, D2, D5 e D8 04

Proposta pedagógica não atende as demandas do mer-

D1, D4, D6 e D13

04

cado de trabalho

Deficiência na organização e condução de componentes curriculares

Inadequada infraestrutura e condições objetivas de D1, D8 e D15

D8, D14, D16 e D3 04 trabalho

Ausência de transposição da proposta pedagógica D1 e D2 para a prática cotidiana

Fonte: tabulação das entrevistas com docentes do CEDF/UEPA

Sobre este aspecto, o registro do sujeito D5 não deixa dúvida sobre o embate de projetos antagônicos presentes na formação, a saber:

Muitos pensadores na escola [CEDF/UEPA] estão esquecendo que lá fora, quando vocês ficarem formados, o dono da academia, o dono da escola particular não vai permitir que vocês façam aquecimento mental, um aquecimento com Paulo Freire, Marx, Lênin, vai querer ver a mercadoria dele, que é o cliente com o qual você irá trabalhar suando e se sentindo bem dentro do espaço de trabalho.

Identificamos que esta incursão não se preocupa em realizar um exame crítico e detido dos determinantes e condicionamentos que forjaram esta lógica muito presente nos espaços privados de trabalho, acabam por satisfazer-se apenas em subsumir sua concepção de formação à lógica do "trabalhador de novo tipo para a gerência da crise do capital" (NOZAKI, 2004, p. 103).

Estes professores, imbuídos na finalidade de profissionalizar a partir de uma perspectiva de inserção efetiva e eficiente dos profissionais de educação física no mercado de trabalho capitalista, fortalecem uma compreensão de educação pelo viés de uma perspectiva conformista, tendo "como pressuposto ontológico a ideia do sujeito atrelado à lógica do mercado, no qual o corpo produtivo é extremamente útil para manter a reprodução e manutenção do capital" (SILVA; PIRES, 2005, p. 2).

Outras questões mencionadas pelos docentes, tais como: a falta de compromisso, de diálogo; de apropriação teórica expressam as próprias contradições das condições objetivas relacionadas ao trabalho; a infraestrutura; a formação do corpo docente, são reveladas e 
relevantes, pois tais aspectos não estão dissociados, mas se materializam como faces da mesma moeda, pois de acordo com Mészáros (2008), o capital como modo de reprodução social metabólica, se expressa como totalidade reguladora sistêmica, logo, a função da educação formal em qualquer instância "é agir como um cão de guarda ex-officio e autoritário para induzir um conformismo generalizado em determinados modos de internalização, de forma a subordiná-los às exigências da ordem estabelecida" (MÉSZÁROS, 2008, p. 55).

Ainda no campo dos limites da proposta de licenciatura ampliada, outro aspecto bastante dimensionado pelos sujeitos foi a ausência e/ou incipiência de componentes curriculares. A reivindicação mais recorrente foi em relação ao universo esportivo, como manifesta o sujeito D6: "o curso de educação física sempre pecou porque sempre houve um exagero para um lado, tempos atrás era só esporte, depois virou só pro lado da educação, então hoje, na minha opinião, tá desequilibrado, a gente tinha que buscar esse equilíbrio". Nesta mesma lógica, o sujeito D10 complementa o pleito informando que "o Projeto Político Pedagógico deixou muitas disciplinas em caráter optativo como o atletismo, a ginástica, os esportes de quadra, como Handebol, Basquete, Vôlei, o Futsal, descaracterizando essa formação ampliada que poderia realmente acontecer".

Segundo Colavolpe (2005) tal modelo, que organiza o esporte no currículo por meio de disciplinas, vem sofrendo críticas há pelo menos duas décadas. A denúncia se fundamenta na compreensão de que o ensino estratificado por modalidades conduz à conformação ideológica e ao adestramento técnico, já que prioriza o esporte como modalidade esportiva competitiva.

Em contraposição, este mesmo autor propõe a lógica do complexo temático em que é concebido como atividade sócio histórica, analisado na contextualização do homem em sociedade, em suas relações de produção da vida, seu comportamento, oportunidades e a compreensão do progresso da história humana como um processo de transmissão ativa das aquisições da cultura através dos processos educativos (COLAVOLPE, 2005).

Discutimos, ainda, as possibilidades indicadas pelos docentes entrevistados, para a Formação em Educação Física, os quais confirmam de maneira indubitável que a disputa no campo da formação humana expressa interesses mais amplos, conectados com a luta pela manutenção ou superação do modo atual de reproduzir a vida em sociedade.

No âmbito do CEDF/UEPA, dos 16 (dezesseis) professores entrevistados, 07 (sete) demonstraram ter abdicado da prerrogativa mais legítima de um professor universitário, a de propor, a partir da observância dos dispositivos reguladores do sistema de ensino, uma proposta pedagógica para a instituição de ensino. Mesmo com as recorrentes advertências do CNE acerca da possibilidade de formação ampliada ensejada pela licenciatura em Educação Física, tem prevalecido entre estes professores as referências de inculcação do sistema CONFEF/CREF, em que a proposta de bacharelado é vista "como lei" (D3, D5, D6, D7, D10, D12) ou "como um direito" (D15).

Segundo Taffarel e Santos Júnior (2010), o processo de internalização predominante da sociedade capitalista tem se reproduzido na educação física através das ações deletérias do sistema CONFEF/CREF, transmitindo "um quadro de valores que legítima os interesses dominantes, como se não pudesse haver nenhuma alternativa à gestão da sociedade" (MÉSZÁROS, 2008, p. 35).

No entanto, conforme evidencia o quadro 4, as possibilidades de propostas formativas apontadas pelos docentes entrevistados são diversas, o que exigirá da comunidade um amplo exercício de organização política para não naturalizar aquilo que é dotado de significado 
social, como o processo de judicialização da relação entre formação acadêmica e exercício profissional.

Tal relação precisa ser coerentemente interpretada sob o ponto de vista jurídico, mas sem tergiversar do aspecto essencialmente político contido na disputa de projetos antagônicos de sociedade, formação e intervenção.

Quadro 4 - Novas propostas para a formação do CEDF/UEPA segundo os docentes

\begin{tabular}{|c|c|c|}
\hline CATEGORIAS EXPLICATIVAS & $\begin{array}{l}\text { RECORRÊN- } \\
\text { CIAS }\end{array}$ & $\mathbf{N}^{\mathbf{0}}$ \\
\hline Fortalecimento da perspectiva da licenciatura ampliada & $\begin{array}{l}\text { D2, D4, D8, } \\
\text { D11 e D16 }\end{array}$ & 05 \\
\hline $\begin{array}{l}\text { Possibilidade de duas modalidades (licenciatura e bacha- } \\
\text { relado) a partir de um único curso }\end{array}$ & $\begin{array}{l}\text { D5, D6, D7, } \\
\text { D12 }\end{array}$ & 04 \\
\hline $\begin{array}{l}\text { Possibilidade de duas modalidades distintas (licenciatura } \\
\text { e bacharelado) }\end{array}$ & $\mathrm{D} 13, \mathrm{D} 14$ e D15 & 03 \\
\hline $\begin{array}{l}\text { Possibilidade de três modalidades distintas (licenciatura, } \\
\text { bacharelado e técnico esportivo) }\end{array}$ & D10 & 01 \\
\hline $\begin{array}{l}\text { Possibilidade de Bacharelado "crítico", atento as deman- } \\
\text { das sociais }\end{array}$ & D9 & 01 \\
\hline $\begin{array}{l}\text { Uma proposta que seja legitimada por toda comunidade } \\
\text { acadêmica }\end{array}$ & D1 & 01 \\
\hline Indeciso sobre a proposta & D3 & 01 \\
\hline
\end{tabular}

Como podemos perceber, as indicações visualizadas no quadro 4 vão do fortalecimento da licenciatura ampliada a pulverização do processo formativo a partir de três modalidades de formação, além das propostas de utopias educacionais, tais como o "bacharelado crítico", o qual visa corrigir as deformidades daquilo que é incorrigível, porém, independente da proposta formativa que vai orientar a política de formação do CEDF/UEPA futuramente, as possibilidades não deixarão de existir, já que os processos formativos apresentam a sua existência determinada, em última instância, pela contradição entre capital e trabalho, logo, enquanto houver classes sociais, o projeto de formação estará em disputa

\section{Considerações finais e novas pautas para a permanência da disputa}

Os princípios orientadores da formação em Educação Física foi a pauta da exposição, com destaque para a discussão inovadora referente a concepção de licenciatura ampliada. Da análise dos dados foi possível ratificar a tese amplamente discutida, de que o campo da formação humana se caracteriza como um setor estratégico para o fortalecimento dos projetos históricos antagônicos.

Os grupos políticos envolvidos demonstram, através de suas ações, que o projeto de formação humana está em disputa e, que no próximo período histórico ou mantêm-se os parâmetros de uma formação aligeirada, precária, exclusivamente instrumental e voltada as demandas do capital ou concebe-se outra base, desta vez, centrada na formação de homens e mulheres protagonistas de sua própria história, conscientes do seu papel na construção de um outro modo de organizar a própria existência, incluindo os elementos da cultura corporal humana. 
O exame dos determinantes desta disputa demonstrou que o sistema CONFEF/CREF é a principal oposição daqueles que lutam por uma formação ampliada na área, logo, o escamoteamento em relação as ações deste conselho profissional tende a fortalecer suas posições, repercutidas nas universidades e, ganhado novos adeptos.

Outro aspecto relevante é que este embate ganhou campo judicial, desta forma, o que tem prevalecido não são as discussões sobre currículo, epistemologia e formação humana, mas sim, questões sobre a "legalidade" da formação ou se, as instâncias da justiça têm sentenciado favoravelmente a tal concepção.

Consequentemente, tal situação tem fragilizado o aspecto mais legítimo das instituições universitárias, que seria pensar as suas propostas formativas. Isto deve-se exclusivamente ao sistema CONFEF/CREF que além de conseguir materializar a fragmentação da formação em Educação Física, concorre com as esferas do sistema de ensino, disciplinando sobre questões que fogem das suas competências.

No universo do CEDF/UEPA, as questões não se demonstraram desconexas das questões mais gerais da área. $\mathrm{O}$ discurso de parcela significativa dos docentes evidenciou o processo de inculcação sofrido, o qual tem imputado ao bacharelado em Educação Física a condição de "modalidade legal" e a licenciatura de caráter ampliado (na essência pedagógicofilosófica) como algo "ilegal", mesmo com um substancial acervo jurídico demonstrando que tal acusação não tem sustentação, devido ao caráter controverso da matéria.

Desta forma, o prognóstico proveniente das discussões sobre a formação na área nos permite indicar que este embate não tem previsão para cessar e que as disputas entre os grupos políticos tendem a se acirrar nas diversas instâncias conformadas, em especial no campo judicial, não cabendo, desta forma, a indiferença daqueles que lutam por um projeto formativo que visa a emancipação humana.

\title{
INITIAL TRAINING IN PHYSICAL EDUCATION AND THE IMPACT OF THE PROPOSAL OF EXPANDED UNDERGRADUATE IN CEDF / UEPA
}

\begin{abstract}
Discusses about the limits and possibilities of implementing a proposal which enlarges the undergraduate CEDF/UEPA. Through bibliographic, documentary and oral sources, it reveals the process of legalization of the impasses related to the Training in Physical Education, the contradictions in the implementation of the formative proposal due to the lack of consensus on the competing projects and the uncritical usage professors make of discourses which do not capture the entire matter relating to Brazilian educational legislation. At last, it concludes pointing to the unfeasibility of consensual outcomes, which requires of those who defende the expanded training proposal the denaturalization of legal and educational interpretations in favor of a political bias.
\end{abstract}

Key-words: Physical Education. Human Resource Training. Higher Education Policy. Curriculum.

\section{FORMACIÓN INICIAL EN EDUCACIÓN FÍSICA Y EL IMPACTO DE LA PRO- PUESTA DE GRAN GRADO CEDF / UEPA}

Resumen:Discute los límites y posibilidades de la aplicación de la medida propuesta asumida por el extendido CEDF/UEPA. A través de referencias bibliográficas, documentales y fuentes orales revela el proceso de legalización de la Formación impasses en Educación Física, las 
contradicciones en aplicación de la propuesta formativa debido a la falta de consenso sobre los proyectos en competencia y la adopción acrítica de los profesores universitarios, los discursos que no captan toda la cuestión relativa a la legislación educativa brasileña. Conclusión sobre la imposibilidad de resultados consensuales, que exige a los defensores de la capacitación propuesta se amplió la desnaturalización de las interpretaciones jurídicas y educativas a favor de una parcialidad política.

Palabras clave: Educación Física. Formación de Recursos Humanos. Superior de Políticas Educativas. Curriculum.

\section{Referências}

ALMEIDA, M. B.; MONTAGNER, P. C.; GUTIERREZ, G. L. A inserção da regulamentação da profissão na área de Educação Física, dez anos depois: embates, debates e perspectivas. Movimento, Porto Alegre, v. 15, n. 3, p. 275-292, jul./set., 2009.

BRASIL. Conselho Nacional de Educação. Câmara de Educação Superior. Parecer n⿳0 135, de 03 de abril de 2002. Consulta sobre a obrigatoriedade de filiação dos professores de Educação Física aos Conselhos Regionais de Educação Física, como condição indispensável ao exercício do Magistério. Disponível em: <http://portal.mec.gov.br/index.php?option=com_content\&view=article\&id=13242\%3Aparec er-ces-2002\&catid=323\%3Aorgaos-vinculados\&Itemid=866> . Acesso em: 27 ago. 2012

BRASIL. Conselho Nacional de Educação. Câmara de Educação Superior. Resoluçãa no 07, de 31 de março de 2004. Institui as Diretrizes Curriculares Nacionais para os cursos de graduação em Educação Física, em nível superior de graduação plena. Brasília, 2004. Disponível em: <http://portal.mec.gov.br/cne/ arquivos/pdf/ces0704edfisica.pdf〉. Acesso em: 27 ago. 2012.

BRASIL. Conselho Nacional de Educação. Câmara de Educação Básica. Parecer no 12, de 02 de agosto de 2005a. Consulta quanto à legalidade do exercício da docência dos profissionais da área de saúde. Disponível em: <http://portal.mec.gov.br/index.php?option=com_content\&view=article\&id=12740\&Itemid= 866>. Acesso em: 27 ago. 2012.

BRASIL. Conselho Nacional de Educação. Câmara de Educação Superior. Parecer n⿳0 400, de 24 de novembro de 2005b. Consulta sobre a aplicação das Diretrizes Curriculares Nacionais para a Formação de Professores da Educação Básica e das Diretrizes Curriculares Nacionais para os cursos de graduação em Educação Física ao curso de Educação Física (licenciatura), tendo em vista a Resolução CONFEF $\mathrm{n}^{\circ}$ 94/2005. Disponível em: $<$ http://portal.mec.gov.br/index.php?option=com_content\&view=article\&id=12700\&Itemid= 866>. Acesso em: 27 ago. 2012.

BRASIL. Conselho Nacional de Educação. Conselho Pleno. Parecer no 6, de 06 de Abril de 2006. Solicita pronunciamento sobre Formação Acadêmica X Exercício Profissional. Disponível em: <http://portal.mec.gov.br/index.php?option=com_content\&view=article\&id=12749\&Itemid= 866>. Acesso em: 27 ago. 2012. 
BRASIL. Conselho Nacional de Educação. Câmara de Educação Superior. Parecer no 82, de 03 de março de 2011a. Solicitação de informações relativas aos cursos de Instrutor e Monitor de Educação Física. Disponível em: $<$ http://portal.mec.gov.br/index.php?option=com_content\&view=article\&id=12991\&Itemid= 866>. Acesso em: 27 ago. 2012.

BRASIL. Conselho Nacional de Educação. Câmara de Educação Superior. Parecer no 274, de 06 de Julho de 2011b. Indicação referente à revisão do texto das Diretrizes Curriculares Nacionais para curso de Graduação em Educação Física. Disponível em: <http://portal.mec.gov.br/index.php?option=com_content\&view=article\&id=16418\&Itemid=866> . Acesso em: 27 ago. 2012.

BRASIL. Conselho Nacional de Educação. Câmara de Educação Superior. Parecer no 255, de 06 de Junho de 2012a. Reexame do Parecer CNE/CES no 400/2005, que trata de consulta sobre a aplicação das Diretrizes Curriculares Nacionais para a Formação de Professores da Educação Básica e das Diretrizes Curriculares Nacionais para os cursos de graduação em Educação Física ao curso de Educação Física (licenciatura), tendo em vista a Resolução CONFEF $\mathrm{n}^{\circ}$ 94/2005. Disponível em: <http://portal.mec.gov.br/index.php?option=com_content\&view=article\&id=17616\&Itemid= 866>. Acesso em: 27 ago. 2012.

BRASIL. Conselho Nacional de Saúde. Resolução no 466, de 12 de Dezembro de 2012b. Diretrizes e normas regulamentadoras de pesquisas envolvendo seres humanos. Disponível em: <http://conselho.saude.gov.br/resolucoes/2012/Reso466.pdf>. Acesso em: 12 jun. 2013.

COLAVOLPE, C. R. O esporte como conteúdo nos cursos de formação de professores: realidade e possibilidades. 2005. 235 f. Dissertação (Mestrado em Educação) - Faculdade de Educação, Universidade Federal da Bahia, Salvador, 2005.

CRUZ, A. C. S. O embate de projetos na formação de professores de educação física: além da dualidade licenciatura - bacharelado. Motrivivência, Florianópolis, Ano XXIII, n. 36, p. 2644, Jun., 2011.

FALCÃO, J. L.C. Para além das metodologias prescritivas na educação física: a possibilidade da capoeira como complexo temático no currículo de formação profissional. Pensar a Prática, Goiânia, v. 7, n. 2, p. 155-170, jul./dez., 2004.

FRIGOTTO, G. O enfoque da dialética materialista histórica na pesquisa educacional. In: FAZENDA, I. (Org.). Metodologia da Pesquisa Educacional. 10. ed. São Paulo: Cortez, 2006. p.70-90.

LEMOS, L. M. et. al. As contradições do processo de elaboração das diretrizes curriculares nacionais dos cursos de formação em Educação Física e os movimentos de resistência à submissão ao mercado. Movimento, Porto Alegre, v. 18, n. 3, p. 27-49, jul./set., 2012.

MÉSZÁROS, I. A educação para além do capital. 2. ed. São Paulo: Boitempo, 2008. 
NOZAKI, H. T. Educação Física e reordenamento no mundo do trabalho: mediações da regulamentação da profissão. 2004. 399 f. Tese (Doutorado em Educação) - Faculdade de Educação, Universidade Federal Fluminense, Niterói, 2004.

SILVA, M. R.; PIRES, G. L. Para além da formação "profissional" em educação física: em defesa da formação humana, Motrivivência, Florianópolis, Ano XVII, n. 25, p. 9-16, dez., 2005 .

TAFFAREL, C. N. Z. Currículo, formação profissional na educação física \& esporte e campos de trabalho em expansão: antagonismos e contradições da prática social. Movimento, Porto Alegre, v. 4, n. 7, p. 43-51, ago./dez., 1997.

TAFFAREL, C. N. Z. A formação profissional e as diretrizes curriculares do programa nacional de graduação: o assalto às consciências e o amoldamento subjetivo, Revista da Educação Física/UEM, Maringá, v. 9, n. 1, p. 13-23, 1998.

TAFFAREL, C. N. Z.; SANTOS JÚNIOR, C. L. Nexos e determinações entre formação de professores de educação física e diretrizes curriculares: competências para quê? In: FIGUEIREDO, Z. C. C. (Org.). Formação profissional em educação física e mundo do trabalho. Vitória: Faculdade Salesiana de Vitória, 2005. p. 111-136.

TAFFAREL, C. N. Z. et al. Formação de professores de educação física para a cidade e o campo. Pensar a Prática, Goiânia, v. 9, n. 2, p. 153-179, jul./dez., 2006.

TAFFAREL, C. N. Z.; SANTOS JÚNIOR, C. L. Formação humana e formação de professores de educação física: para além da falsa dicotomia licenciatura $x$ bacharelado. In: TERRA, D. V.; SOUZA JUNIOR, M. Formação em educação física \& ciências do esporte: políticas e cotidiano. São Paulo: Aderaldo \& Rothschil: Goiânia: CBCE, 2010. p. 13-48.

TAFFAREL, C. N. Z. Formação de professores de educação física: diretrizes para a formação unificada. Kinesis, Santa Maria, v. 30, n. 1, p. 95-133, jan./jun., 2012.

UEPA. Projeto político pedagógico do curso de educação física. Belém: CEDF/UEPA, 2007.

Recebido em: 24/04/2014

Revisado em:1410/2014

Aprovado em: 09/03/2015

Endereço para correspondência:

anibalcbn@yahoo.com.br

Anibal Correia Brito Neto

Universidade do Estado do Pará, Curso de Educação Física.

Av. João Paulo II, 817

Marco

66095490 - Belem, PA - Brasil 